\title{
Congenital Cytomegalovirus Infection Presenting as Pneumonia with Respiratory Distress and Thrombocytopenia
}

\author{
Nipun Shrestha, Bhabuk Sharma Majagaiya, Dhruba Shrestha
}

Siddhi Memorial Hospital (for Women and Children), Bhaktapur, Nepal

\section{Email address:}

nipsam@hotmail.com (N. Shrestha)

\section{To cite this article:}

Nipun Shrestha, Bhabuk Sharma Majagaiya, Dhruba Shrestha. Congenital Cytomegalovirus Infection Presenting as Pneumonia with Respiratory Distress and Thrombocytopenia. American Journal of Pediatrics. Vol. 5, No. 4, 2019, pp. 230-233. doi: $10.11648 /$ j.ajp.20190504.21

Received: August 12, 2019; Accepted: September 6, 2019; Published: October 23, 2019

\begin{abstract}
Human Cytomegalovirus (CMV) is a member of Herpes viridae family, that affects most of the human population at some stage of live and is the most common congenital infection causing sensorineural hearing loss and neurodevelopmental delay in newborn. CMV infection may be acquired in a newborn congenitally or after delivery, but except for the congenital infection, other mode of infection rarely result in significant symptoms or sequel in them. Clinical findings of congenital CMV infection include IUGR, hydrops, generalized petechiae, purpura, thrombocytopenia, jaundice, hepatosplenomegaly, pneumonitis, microcephaly, periventricular calcifications, seizures, chorioretinitis, sensorineural hearing loss, bone abnormalities, abnormal dentition, and hypocalcified enamel. Here we present a case of congenital CMV infection who presented with Pneumonia with Respiratory distress and thrombocytopenia. A single, live, term, female child delivered at home developed low grade fever, cough and increased oral secretion at 28 day of life and was initially diagnosed as Pneumonia with respiratory distress with thrombocytopenia. Mother and child, both were investigated for TORCH infection which came out to be positive for CMV infection (child's serum CMV Ab IgM 94 U/ml). Her CMV Viral Load Real Time PCR tested positive with 56380 copies $/ \mathrm{ml}$.
\end{abstract}

Keywords: Human Cytomegalovirus, Herpes Viridae, Thrombocytopenia, TORCH

\section{Introduction}

Human Cytomegalovirus (CMV) is a member of Herpes viridae family, that affects most of the human population at some stage of live and is the most common congenital infection causing sensorineural hearing loss and neurodevelopmental delay in newborn. [1] The virus is shed from infected person through saliva, blood, urine, breastmilk and genital secretion and maternal transmission to fetus can occur at any age of gestation. [2] CMV infection may be acquired in a newborn congenitally or after delivery, but except for the congenital infection, other mode of infection rarely result in significant symptoms or sequel in them. [3] Clinical findings of congenital CMV infection include IUGR, hydrops, generalized petechiae, purpura, thrombocytopenia, jaundice, hepatosplenomegaly, pneumonitis, microcephaly, periventricular calcifications, seizures, chorioretinitis, sensorineural hearing loss, bone abnormalities, abnormal dentition, and hypocalcified enamel. [2]

\section{Case}

A single, live, term, female child was delivered vaginally at home with birth weight of $2.5 \mathrm{~kg}$. The mother was a Primigravida who was doing her regular antenatal care (ANC) in a hospital in Solukhumbu, Nepal. She had uneventful pregnancy (i.e no History of Pregnancy Induced Hypertension, Gestational Hypertension or Hyperemesis Gravidum) and had regularly taken Folic Acid during first trimester and was taking Iron and Calcium since her second trimester. At 28 day of life, the child developed low grade fever, Cough and increased oral secretion, for which she was taken to local hospital where she was diagnosed as 
Pneumonia in respiratory distress. She was then referred to tertiary center for further evaluation and management. The Child was initially treated with Injection vancomycin and Injection meropenem at one hospital in Kathmandu, but was then referred to our center for NICU care.

On arrival to our center, the child appeared sick with increased respiratory rate (70 breath/minute) and with increased respiratory effort suggested by marked subcoastal retraction and nasal flaring and decreased $\mathrm{SPO}_{2}(70 \%$ in Room Air). She had bilateral Basal Crepitations on chest auscultation. The chest xray showed Bilateral Pneumonia. Her Blood reports are as follows: TLC 13200/cmm, N36\%, L61\%, Hb 14.9g/dl, Platelet 30000/cmm, CRP <6mg/l, PT 16 sec, Control $14 \mathrm{sec}$, INR 1.2, APTT 37Sec, RBS 56mg/dl, Urea $33 \mathrm{mg} / \mathrm{dl}$, Creatinine $128 \mathrm{mg} / \mathrm{dl}$, Na $128 \mathrm{mmol} / \mathrm{l}$, K 4.2 $\mathrm{mmol} / \mathrm{l}$. The Arterial Blood Gas analysis showed $\mathrm{pH} 7.331$, $\mathrm{PCO}_{2} 50.9 \mathrm{mmHg}, \mathrm{PO}_{2} \mathrm{mmHg}, \mathrm{stHCO}_{3} 25.6 \mathrm{mmol} / \mathrm{l}$. She was then kept under CPAP with PEEP of $5 \mathrm{cmH}_{2} \mathrm{O}$ and Inj
Meropenem and Inj Vancomycin were continued. The child showed some signs of improvement in first 3 days of admission but the platelet count wasn't improving as expected. Emperical Antifungal (Inj fluconazole) was added as well with a suspicion of probable Fungal Infection. Inj dexamethasone was added as well on 6th day of admission. Mother and child, both were investigated for TORCH infection which came out to be positive for CMV infection (child's serum CMV Ab IgM 94 U/ml). Her CMV Viral Load Real Time PCR tested positive with 56380 copies $/ \mathrm{ml}$ (positive result if $>10000$ copies $/ \mathrm{ml}$ ). The final diagnosis of CMV pneumonitis was made. Tab Valgancyclovir was started. CPAP was stopped on 12th day of admission, but the child still needed $\mathrm{O}_{2}$ via nasal prong @2 $21 / \mathrm{min}$. The child managed to maintain $\mathrm{SPO}_{2}$ with free flow $\mathrm{O}_{2}$ before discharge. The detailed Laboratory Reports during the whole course of treatment is expressed in Table 1. The child had a total ICU stay of 26 days and total hospital stay of 48 days.

Table 1. Detailed Laboratory Reports.

\begin{tabular}{|c|c|c|c|c|c|}
\hline Date & 31/3/2019 & 4/4/2019 & $8 / 4 / 2019$ & 9/4/2019 & $13 / 4 / 2019$ \\
\hline Total Leucocyte Count (/cmm) & 13200 & 12800 & 7100 & & \\
\hline Neutrophil/ Lymphocyte (\%) & $36 / 61$ & $28 / 71$ & $36 / 64$ & & \\
\hline $\mathrm{Hb}(\mathrm{g} / \mathrm{dl})$ & 14.9 & 13 & 11.5 & & \\
\hline Platelet (/cmm) & 30000 & 71000 & 153000 & & \\
\hline $\mathrm{CRP}(\mathrm{mg} / \mathrm{l})$ & $<6$ & 12 & $<6$ & & \\
\hline PT/Control/APTT (sec) & $16 / 14 / 37$ & & & & \\
\hline Urea/ Creatinine (mg/dl) & $33 / 0.6$ & & & & \\
\hline $\mathrm{Na} / \mathrm{K}(\mathrm{mmol} / \mathrm{l})$ & $128 / 4.2$ & & & & \\
\hline TSB/ DSB (mg/dl) & $2.1 / 1.6$ & & & & \\
\hline SGPT/SGOT/ALP (U/l) & $160 / 300 / 140$ & & & & \\
\hline Total protein/Albumin (g/dl) & $6.0 / 3.6$ & & & & \\
\hline Blood Culture & No Growth & & & & \\
\hline CSF analysis & & $\begin{array}{l}\text { TLC } 3 \text { cell/cmm, } 100 \% \text { Lymphocyte, G } 40 \mathrm{mg} / \mathrm{dl} \text {, } \\
\text { P } 138 \mathrm{mg} / \mathrm{dl} \text {, No microorganism in Gram Stain, } \\
\text { AFB not seen, No growth In culture }\end{array}$ & & & \\
\hline Mantoux Test & & & Negative & & \\
\hline CMV IgM Ab (U/ml) & & & & 94.5 & \\
\hline CMV viral load PCR (copies $/ \mathrm{ml}$ ) & & & & & 56380 \\
\hline
\end{tabular}

The chest Xray during the whole course of treatment, in order from date of admission to the date of discharge, is expressed in Figure 1.
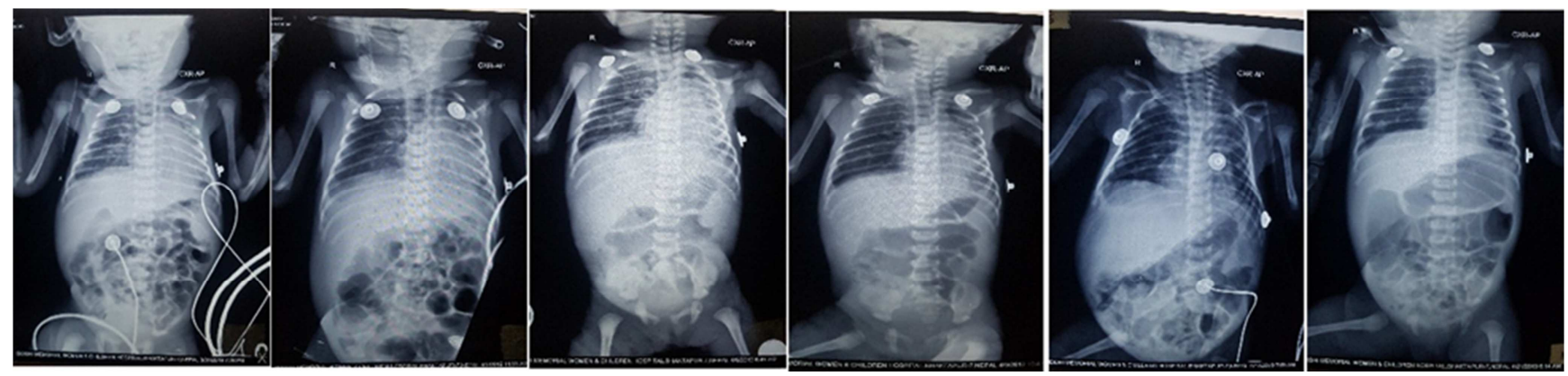

Figure 1. CXR from admission to before discharge.

\section{Discussion}

CMV infection is a global problem and seropositivity can be found in more than $45 \%$ of women of reproductive age, mainly in the developing countries. [4, 5] Transmission of CMV infection from mother to fetus can occur at any stage of pregnancy, but the severe adverse fetal outcome is seen if it is transmitted to fetus in 1 st half of pregnancy. [6] It is estimated that about $40-58 \%$ of newborn with congenital CMV infection who are symptomatic at the time of birth will develop some form of sequelae like Sensorineural hearing loss, vision loss, mental reatardation etc. [7-10] The infection 
in fetus is diagnosed by positive viral culture or PCR from amniotic fluid and the infection in the neonate is diagnosed by viral detection in body fluids via PCR, culture, or antigen testing within the first 3 weeks of life. [11] The preferred samples are saliva or urine as they are easy to obtain and equally reliable. [12-13]

\section{Conclusion}

Congenital CMV infection is a global problem and should be considered in all neonates with suspected sepsis, especially in developing countries. The probability of having TORCH infection could be high in those who doesn't respond well to commonly used antibiotics and antifungals. Congenital CMV infection could present in many ways, thrombocytopenia and pneumonia being one presentation that doesn't respond well to antibiotics and antifungals, and require specific treatment.

\section{Abbreviations}

ANC: Antenatal Care

APTT: Activated Partial Thromboplastin Time

CMV: Cytomegalovirus

CPAP: Continious Positive Airway Pressure

CRP: C-Reactive Protein

$\mathrm{Hb}$ : Hemoglobin

$\mathrm{HCO}_{3}$ : Bicarbonate

INR: International Normalized Ratio

IUGR: Intrauterine Growth Restriction

$\mathrm{K}$ : Potassium

L\%: Lymphocyte Percentage

N\%: Neutrophil Percentage

Na: Sodium

NICU: Neonatal Intensive Care Unit

$\mathrm{O}_{2}$ : Oxygen

$\mathrm{PCO}_{2}$ : Partial Pressure of Carbondioxide

PCR: Polymerase Chain Reaction

PEEP: Positive End Expiratory Pressure

$\mathrm{pH}$ : pouvoir hydrogène (power of Hydrogen)

$\mathrm{PO}_{2}$ : Partial Pressure of Oxygen

PT: Prothrombin Time

RBS: Random Blood Sugar

$\mathrm{SPO}_{2}$ : Peripheral capillary oxygen saturation

TLC: Total Leucocyte Count

TORCH: Toxoplasmosis, Others, Rubella Cytomegalovirus, Herpes simplex, and HIV.

\section{Informed Consent}

1. The consent of the parents of the child is taken for the publication of the case.

2. The privacy of the child and family will be maintained. The information about the child and family will not be exposed to other people and will be confined to case study report only.

\section{Acknowledgements}

I would like to thank Dr Dhruba Shrestha, Head of Department, Pediatrics, Siddhi Memorial Hospital (for women and children) who supervised and helped me throughout while working on this case study. I could not have imagined having a better advisor and mentor for this study.

I would also like to thank my fellow labmates, staff nurses and my colleagues in for the stimulating discussions, for the time we were working together. Also I thank my wife Dr. Mala Shrestha who supported me in many ways.

\section{References}

[1] Van Zuylen WJ, Hamilton ST, Naing Z, Hall B, Shand A, Rawlinson WD. Congenital cytomegalovirus infection: Clinical presentation, epidemiology, diagnosis and prevention. Obstetric medicine. 2014 Dec; 7 (4): 140-6.

[2] Swanson EC, Schleiss MR. Congenital cytomegalovirus infection: new prospects for prevention and therapy. Pediatric Clinics. 2013 Apr 1; 60 (2): 335-49.

[3] Schleiss MR. Acquisition of human cytomegalovirus infection in infants via breast milk: natural immunization or cause for concern? Reviews in medical virology. 2006 Mar; 16 (2): $73-$ 82 .

[4] Manicklal S, Emery VC, Lazzarotto T, et al. The "silent" global burden of congenital cytomegalovirus. Clin Microbiol Rev 2013; 26: 86-102.

[5] Cannon MJ, Schmid DS and Hyde TB. Review of cytomegalovirus seroprevalence and demographic characteristics associated with infection. Rev Med Virol 2010; 20: 202-213.

[6] Pass RF, Fowler KB, Boppana SB, et al. Congenital cytomegalovirus infection following first trimester maternal infection: symptoms at birth and outcome. J Clin Virol 2006; 35: 216-220.

[7] Dollard SC, Grosse SD, Ross DS. New estimates of the prevalence of neurological and sensory sequelae and mortality associated with congenital cytomegalovirus infection. Rev Med Virol. 2007; 17 (5): 355-363. [PubMed: 17542052].

[8] Boppana SB, Pass RF, Britt WJ, et al. Symptomatic congenital cytomegalovirus infection: neonatal morbidity and mortality. Pediatr Infect Dis J. 1992; 11 (2): 93-99.

[9] Conboy TJ, Pass RF, Stagno S, et al. Early clinical manifestations and intellectual outcome in children with symptomatic congenital cytomegalovirus infection. J Pediatr. 1987; 111 (3): 343-348.

[10] Pass RF, Stagno S, Myers GJ, et al. Outcome of symptomatic congenital cytomegalovirus infection: results of long-term longitudinal follow-up. Pediatrics. 1980; 66 (5): 758-762.

[11] Bhatia P, Narang A, Minz RW. Neonatal cytomegalovirus infection: diagnostic modalities available for early disease detection. Indian J Pediatr. 2010; 77 (1): 77-79.

[12] Boppana SB, Ross SA, Shimamura M, et al. Saliva polymerasechain-reaction assay for cytomegalovirus screening in newborns. N Engl J Med. 2011; 364 (22): 2111-2118. 
[13] Yamamoto AY, Mussi-Pinhata MM, Marin LJ, et al. Is saliva as reliable as urine for detection of cytomegalovirus DNA for neonatal screening of congenital CMV infection? Journal of clinical virology: the official publication of the Pan American Society for Clinical Virology. 2006; 36 (3): 228-230.

\section{Biography}

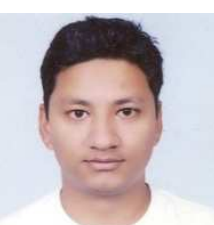

Name: Dr Nipun Shrestha

Specialization: MD Pediatrics

Rank: Senior Registrar Pediatrician

Place of Work: Siddhi Memorial Hospital (for women and children)

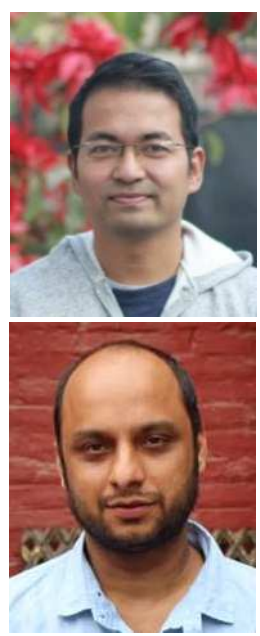

Name: Dr Dhruba Shrestha

Specialization: MD Pediatrics

Rank: Consultant Pediatrician, Head of Department

Place of Work: Siddhi Memorial Hospital (for women and children)

Name: Dr Bhabuk Sharma Majagaiya

Specialization: MD Pediatrics

Rank: Registrar Pediatrician

Place of Work: Siddhi Memorial Hospital (for women and children) 